\title{
Rancang Bangun Traffic Light System Tanggap Darurat Berbasis IoT
}

\author{
Usman $^{1}$, Panjaitan Albert ${ }^{1}$, Indah Vusvita Sari ${ }^{1}$, Iswandi Idris ${ }^{2, *}$, Rizaldy Khair ${ }^{2}$ \\ ${ }^{1}$ Teknik Listrik Bandar Udara, Politeknik Penerbangan Medan, Medan, Indonesia \\ ${ }^{2}$ Teknologi Komputer, Politeknik LP3I Medan \\ Email: ${ }^{1}$ usmanatkp@yahoo.co.id, ${ }^{2}$ albertpanjaitan20@gmail.com, ${ }^{3}$ indahvusvita@gmail.com, ${ }^{4, * i s w a n d i . i d r i s @ ~}$ plm.ac.id, \\ 5rizaldyk.lp3i@gmail.com \\ Email Penulis Korespondensi: iswandi.idris@plm.ac.id
}

\begin{abstract}
Abstrak-Pada persimpangan jalan baik persimpangan tiga maupun persimpangan empat yang memiliki lampu lalu lintas sering terjadi kepadatan kendaraan. Tentu saja hal tersebut dapat menghambat kinerja kendaraan prioritas yang akan melintas di persimpangan. Untuk mengatasi hal tersebut maka peneliti merancang sebuah sistem mikrokontroler lampu lalu lintas mengunakan sensor suara. Sensor suara merupakan teknologi identifikasi otomatis yang menggunakan gelombang suara yang mengenai membran sensor yang menyebabkan bergeraknya membran sensor yang memiliki kumparan kecil dibalik membran tersebut naik dan turun maka sensor tersebut akan terhubung dengan lampu disetiap persimpangan jalan parkir bandara sehingga lampu lalu lintas area parkir maupun terminal kedatangan atau pelepasan berganti secara otomatis.Tujuan penelitian ini yaitu diharapkan dapat menghasilkan suatu rancang bangun sistem lampu lalu lintas yang memanfaatkan IOT teknologi sensor suara terhadap kepadatan kendaraan yang berada di persimpangan jalan baik simpang tiga atau simpang empat agar dapat diatur kelancaran lalu lintas kendaraan dan hal hal kendaraan darurat (ambulan, mobil pemadam kebakaran atau pejabat) dapat bekerja secara tepat waktu dan maksimal, , Luaran yang dihasilkan adalah produk prototype IOT dan publikasi ke jurnal
\end{abstract}

Kata Kunci: Sensor Suara, Arduino, Lampu Lalu Lintas, Tanggap Darurat.

Abstract-At crossroads, both crossing three and crossing four which have traffic lights, there is often heavy traffic. Of course this can hamper the performance of priority vehicles that will cross the intersection. To overcome this, the researchers designed a traffic light microcontroller system using a sound sensor. Sound sensor is an automatic identification technology that uses sound waves that hit the sensor membrane which causes the sensor membrane to move which has a small coil behind the membrane up and down then the sensor will be connected to the lights at each airport parking road junction so that the traffic lights of the parking area and arrival terminal or the release changes automatically. The purpose of this study is expected to produce a traffic light system design that utilizes IOT sound sensor technology to the density of vehicles that are at a crossroads either intersection three or intersection four in order to regulate the smooth flow of vehicles and things emergency vehicles (ambulances, fire engines or officials) can work on time and at the maximum, The output produced is a prototype IoT product and publication to journal.

Keywords: Sound Sensor, Arduino, Traffic Lights, Emergency Response.

\section{PENDAHULUAN}

Persoalan kemacetan lalu lintas saat ini menjadi masalah transportasi yang dialami oleh hampir seluruh kotakota besar di dunia, termasuk kota-kota besar di Indonesia. Kemacetan disebabkan oleh beberapa faktor, diantaranya lampu lalu lintas yang berfungsi sebagai pengatur arus perempatan jalan tidak berfungsi dengan efisien. Pada persimpangan yang menggunakan alat pemberi isyarat lalu lintas, konflik antar arus lalu lintas dikendalikan dengan isyarat lampu [1]

Seiring dengan berkembangnya penduduk, kemacetan lalu lintas tidak lagi dapat dihindarkan terutama pada persimpangan. Waktu paling rawan terjadi kemacetan lalu lintas adalah pada jam berangkat kerja dan pulang kerja, sehingga kendaraan yang diprioritaskan terhambat pada perempataan lalu lintas. hal inilah yang membuat fungsi dari lampu lalu lintas sebagai pengatur arus kendaraan menjadi kurang efisien. Simpang jalan akan memunculkan problematik berupa konflik antar kendaraan yang masuk ke simpang, kemacetan lalu lintas, kecelakaan lalu lintas, antrian, tundaan dan lain sebagainya [2]. Salah satu penumpukan kendaraan bermotor yang menyebabkan kemacetan ini, dikarenakan antrian kendaraan bermotor pada saat lampu lalu lintas berwarna merah [3].

Dalam Pasal 134 diatur bahwa pengguna Jalan yang memperoleh hak utama untuk didahulukan sesuai antara lain: Kendaraan pemadam kebakaran yang sedang melaksanakan tugas; Ambulans yang mengangkut orang sakit; Kendaraan untuk memberikan pertolongan pada Kecelakaan Lalu Lintas [4]. Kendaraan darurat sangat membutuhkan waktu yang seminimal mungkin dalam perjalanan agar pertolongan atau keperluan darurat segera dapat dipenuhi. Kendaraan darurat mempunyai kepentingan yang harus di prioritaskan dari pada pengguna jalan yang lain yaitu kendaraan pribadi, kendaraan umum dan pejalan kaki. Maka dari itu bantuan teknologi sangat diperlukan untuk diterapkan pada setiap persimpangan yang memiliki lampu lalu lintas, agar memudahkan kinerja petugas kendaraan darurat. Pada penelitian terdahulu "Rancang Bangun Sistem Respon Lampu Lalu Lintas Berdasarkan Kondisi Darurat Mengunakan Teknologi RFID”, Perancangan tersebut menginstal semua program yang digunakan untuk memberi instruksi pada persimpangan jalan, sehingga dengan mudah kendaraan darurat melewati persimpangan [3].

Perancangan sistem respon lampu lalu lintas dikembangkan dengan tujuan untuk mengendalikan lampu lalu lintas yang dapat menyesuaikan keadaan lalu lintas di sekitarnya. Dengan adanya suatu sistem yang baik, 
maka peneliti mengharapkan dapat menghasilkan pengendali lalu lintas sebaik mungkin, teratur, dan optimal sehingga dapat meningkatkan efisiensi dan efektifitas dari lampu lalu lintas itu sendiri, yang pada akhirnya dapat mengurangi kemacetan dan menambah efisiensi waktu dan kendaraan prioritas tetap diutamakan.

\section{METODE PENELITIAN}

Prosedur pengumpulan data pada penelitian ini adalah :

1. Penelitian Lapangan (Field Research) adalah mengumpulkan data-data tentang objek penelitian di lapangan atau di lokasi objek penelitian yang terdiri dari [5] :

a. Observasi, dilengkapi dengan lembar keterangan yang berisi informasi aspek- spek yang di observasi.[6]

b. Wawancara terstruktur, dilengkapi dengan daftar wawancara, nama dan tandatangan.

2. Penelitian Kepustakaan (Library Research).

\section{HASIL DAN PEMBAHASAN}

Berikut ini adalah disain rangkaian assembly (sensor suara - LED dan Buzzer)

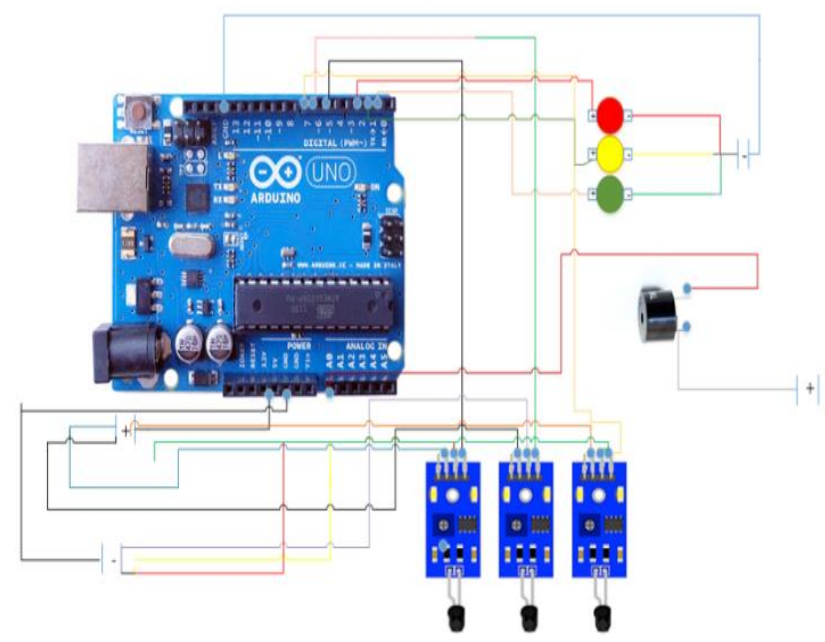

Gambar 1. Disain Keseluruhan Rangkaian

Keterangan :

1. Pin 2 pada arduino [7] dihubungkan pada LED merah.

2. Pin 3 pada arduino dihubungkan pada LED kuning.

3. Pin 4 pada arduino dihubungkan pada LED hijau.

4. A0 pada arduino dihubungan ke buzzer.

5. Pin 5 pada arduino dihubungkan ke kaki sensor suara 1 module A0.

6. Pin 6 pada arduino dihubungkan ke kaki sensor suara 2 module A0

7. Pin 7 pada arduino dihubungkan ke kaki sensor suara 3 module A0

8. $5 \mathrm{v}$ pada arduino yaitu mengambil arus positif pada rangkaian.

9. GND pada arduino yaitu mengambil arus negatif pada rangkaian.

$10.5 \mathrm{~V}$ pada arduino untuk mengambil arus positif pada rangkaian.

11. GND pada arduino yaitu mengambil arus negatif pada rangkaian

Pada gambar berikut terlihat desain sistem, perangkat yang di bangun.

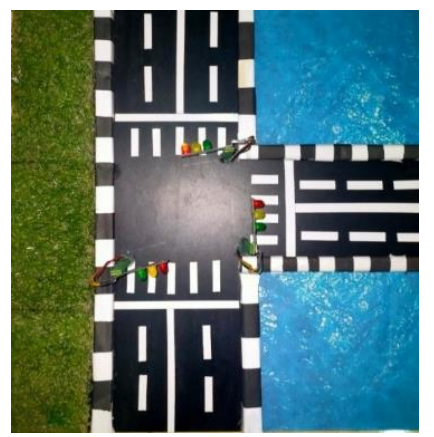

Gambar 2. Prototype Disain Sistem 


\subsection{Rancangan Flowchart}

Berikut ini ditampilkan flowchart perancangan sistem secara umum bagaimana respon lampu lalu lintas ketika sebuah kendaraan darurat ingin melintasi persimpangan.

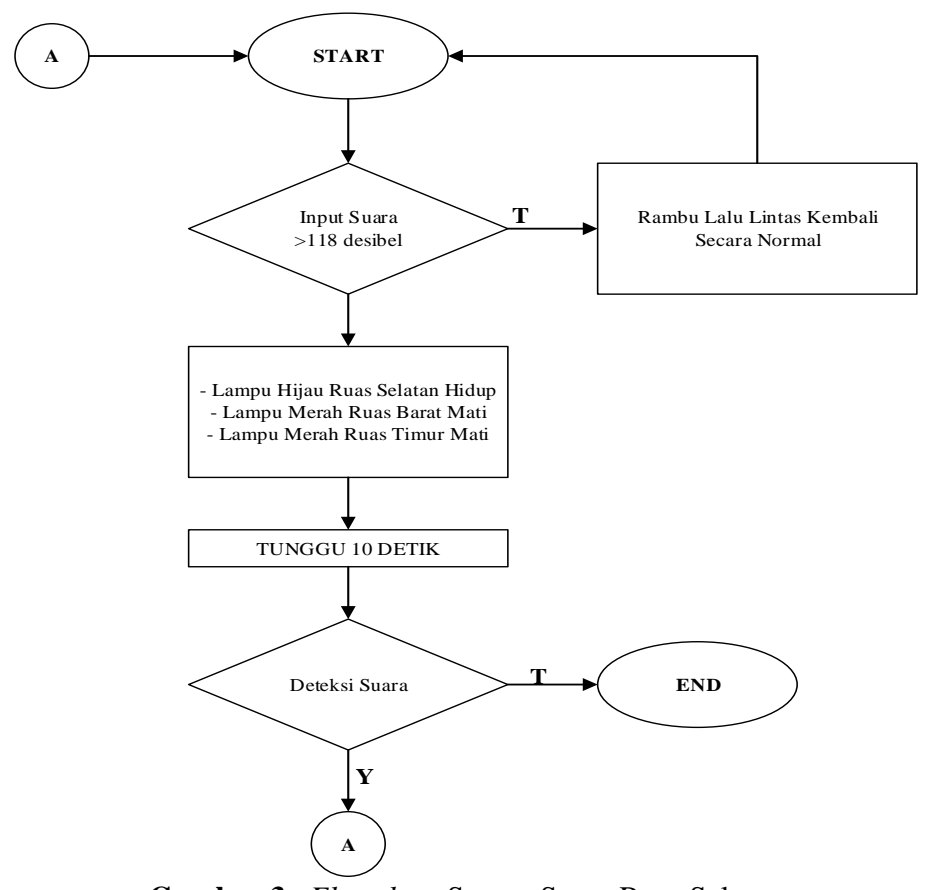

Gambar 3. Flowchart Sensor Suara Ruas Selatan

Hasil Analisis Arduino UNO, dapat dilihat pada tabel 1, berikut.

Tabel 1. Hasil Analisa Arduino Uno

\begin{tabular}{cccccccccc}
\hline No & \multicolumn{3}{c}{ Input } & \multicolumn{3}{c}{ Receive Data } & Output & \\
\cline { 2 - 9 } & $\begin{array}{c}\text { Sensor } \\
1\end{array}$ & $\begin{array}{c}\text { Sensor } \\
2\end{array}$ & $\begin{array}{c}\text { Sensor } \\
3\end{array}$ & $\begin{array}{c}\text { Kekerasan } \\
\text { Suara } \\
\text { (Desibel) }\end{array}$ & $\begin{array}{c}\text { Kekerasan } \\
\text { Suara } \\
\text { (Desibel) }\end{array}$ & $\begin{array}{c}\text { Kekerasan } \\
\text { Suara } \\
(\text { Desibel) }\end{array}$ & $\begin{array}{c}\text { Lampu } \\
\text { Sensor 1 }\end{array}$ & $\begin{array}{c}\text { Lampu } \\
\text { Sensor 2 }\end{array}$ & $\begin{array}{c}\text { Lampu } \\
\text { Sensor 3 }\end{array}$ \\
\hline 1 & True & False & False & 135 & 80 & 70 & Hijau & Merah & Merah \\
\hline 2 & False & True & False & 60 & 140 & 65 & Merah & Hijau & Merah \\
\hline 3 & False & False & True & 50 & 35 & 125 & Merah & Merah & Hijau \\
\hline
\end{tabular}

Hasil Analisis Logika Alat terlihat pada tabel 2.

Tabel 2. Hasil Analisa Logika Alat

\begin{tabular}{ccccc}
\hline $\begin{array}{c}\text { Kekerasan Suara } \\
\text { (Desibel) }\end{array}$ & Sensor Suara & MERAH & $\begin{array}{c}\text { OUTPUT ( LAMPU ) } \\
\text { KUNING }\end{array}$ & HIJAU \\
\hline 110 & FALSE & $\mathrm{X}$ & $\mathrm{X}$ & $\mathrm{X}$ \\
120 & TRUE & $\mathrm{X}$ & $\mathrm{X}$ & $\mathrm{V}$ \\
135 & TRUE & $\mathrm{X}$ & $\mathrm{X}$ & $\mathrm{V}$ \\
105 & FALSE & $\mathrm{V}$ & $\mathrm{X}$ & $\mathrm{X}$ \\
90 & FALSE & $\mathrm{V}$ & $\mathrm{X}$ & $\mathrm{X}$ \\
\hline
\end{tabular}

Berdasarkan Tabel 2 diatas dapat dilihat bahwa untuk mengaktifkan lampu tersebut hanya dapat dilakukan dengan sensor yang mendeteksi kekerasan suara sebesar 118 desibel dan masing-masing LED juga akan menyala ketika kekerasan yang ditentukan tercapai. Hasil pengukuran ini juga sesuai dengan perancangan sistem yang mengatur sensor untuk mengubah lampu lalu lintas tersebut.

\subsection{Implementasi}

Setelah dilakukan pengujian alat, maka dapat kita ketahui apakah sistem sudah berjalan dengan baik apa belum. Proses awal pada alat adalah lampu lalu lintas akan menyala secara bergantian dimulai dari arah selatan lampu hijau menyala, kemudian arah timur dan barat lampu merah menyala. Setelah itu arah timur lampu hijau menyala, kemudian arah barat dan selatan lampu merah menyala, dan arah barat lampu hijau menyala, kemudian arah timur dan selatan lampu merah menyala. Proses selanjutnya yaitu peletakan sensor suara 1 diarah barat, sensor suara 2 diarah selatan dan sensor suara 3 diarah timur yang jarak sensor terpasang kurang lebih 100 meter dibadan jalan. Ketika sebuah kendaraan darurat membunyikan suara sirine dari arah barat tentu saja akan 
melintasi sensor suara 1. Setelah melintasi sensor suara 1 secara otomatis kondisi lampu lalu lintas arah barat akan berubah menyala berwarna hijau kemudian lampu lalu lintas arah selatan dan timur menyala berwarna merah. Kemudian jalan yang dilewati oleh kendaraan darurat di berikan delay selama 10 detik setelah itu maka rambu lalu lintas bekerja seperti proses awal.

Letak posisi sensor suara tersebut adalah pendeteksi utama dari pada lampu lalu lintas adaptif. Sensor akan bekerja dengan baik apabila dia menangkap suara sirine tersebut secara otomtis lampu akan berganti maka menangkap suara tingkat kekerasan minimal 118 desibel.

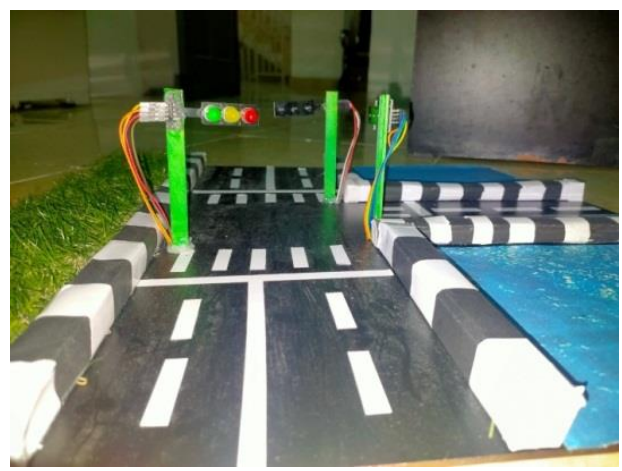

Gambar 4. Tampilan prototipe Traffic Light System Tanggap Darurat

Dari dambar 4 terlihat sebuah persimpangan jalan raya yang ada lampu merah, dalam simulasi ketika mobil prioritas (ambulance) melewati lampu merah maka petugas ambulance mengaktifkan menu aplikasi emergency traffic light seperti terlihat pada Gambar 5 dibawah ini

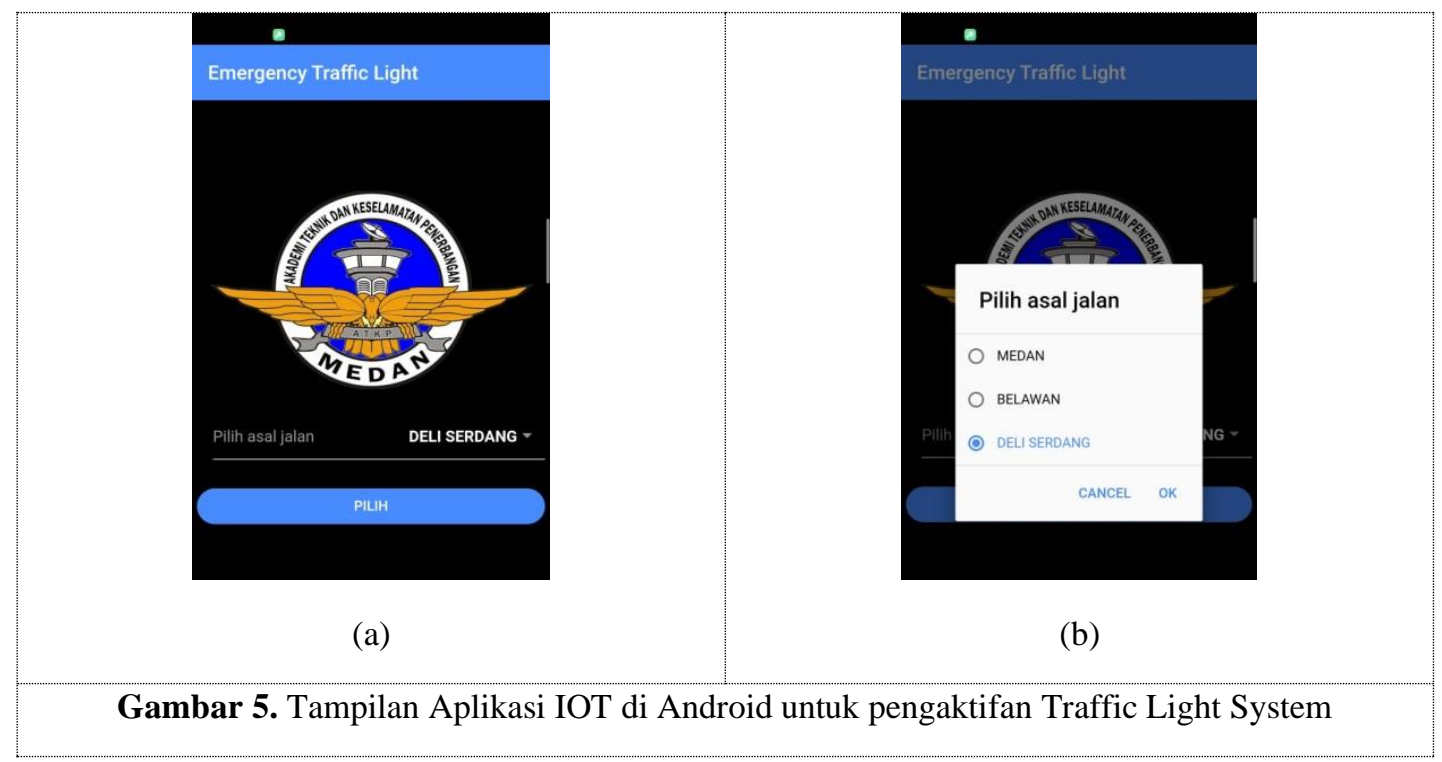

\section{KESIMPULAN}

Berdasarkan penjelasan diatas penulis dapat mengambil kesimpulan bahwa lampu lalu lintas secara otomatis akan merespon ketika tingkat kekerasan sirine diatas 118 desibel dan apabila tingkat kekerasan sirine yang dibunyikan dibawah 118 desibel maka sensor tersebut tidak akan merespon. Selain itu, pengontrolan rambu lalu lintas otomatis ini dapat mempermudah para petugas yang ada di setiap persimpangan sehingga tidak perlu mengatur kendaraan prioritas melewati setiap persimpangan. Penulis berharapkan agar adanya pengujian lebih lanjut tentang penggunaan lampu lalu lintas berbasis mikrokontroler yang lainnya, sehingga bisa terlihat perbedaannya. Sehingga dapat memberikan hasil yang lebih efektif. Penulis juga merasa perlunya pengembangan pengaturan lampu lalu lintas menggunakan sensor sebagai salah satu upaya dalam mengantisipasi kepadatan lalu lintas yang disebabkan oleh banyaknya jumlah kendaraan.

\section{REFERENCES}

[1] A. Alhadar, "Analisis kinerja jalan dalam upaya mengatasi kemacetan lalu lintas pada ruas simpang bersinyal di kota palu," Smartek, vol. 9 , no. 4, 2011

[2] M. I. Febriyanto, "PERENCANAAN SIMPANG DENGAN MENGGUNAKAN LAMPU LALU LINTAS,” J. Tek. Ind. Terintegrasi, 
vol. 1, no. 1, pp. 41-45, 2018.

[3] D. Hartanti and W. H. Martono, "PENETAPAN TITIK PENDETEKSI ANTRIAN KENDARAAN PADA PEREMPATAN LAMPU LALU LINTAS," Kilat, vol. 5, no. 2, 2016.

[4] A. Zamzami, "KEADILAN DI JALAN RAYA Abid,” Yurispruden, vol. 1, no. 2, pp. 17-34, 2018.

[5] B. P. R. K. I. Hermawan, "Motorcycle safety technology with iot," J. Online Jar. Pengaj. Seni Bina, vol. 10, no. 1, pp. 116-120, 2017.

[6] M. Zikri and R. Khair, "Rancang Bangun Monitoring Polusi Udara Berbasis Arduino," J. Teknovasi J. Tek. dan Inov., vol. 5, no. 1, pp. 27-38, 2018.

[7] M. S. Hasibuan, Syafriwel, and I. Idris, "Intelligent LPG Gas Leak Detection Tool with SMS Notification," J. Phys. Conf. Ser., vol. 1424 , no. $1,2019$. 